\title{
Gender-wise contribution in carbon management by high himalayan ethnic group of Gatlang VDC, Rasuwa, Nepal
}

\author{
Rashila Deshar* and Madan Koirala
}

Central Department of Environmental Science, Tribhuvan University, Kirtipur, Nepal

\begin{abstract}
In mountainous country Nepal having large populations of culturally unique indigenous peoples poses threats of glaciers retreat and resource bases change. The indigenous people living in mountain plays the major role in carbon management. Further, the role and responsibilities of men and women varies differently in natural resource conservation and management. However, their participation in decisionmaking and benefit sharing is poor. The majority of women have unequal access to productive resources and decision-making process. Therefore, study on gender based agro-pastoral activities, their contribution on carbon management and decision making process were carried out in Tamang ethnic group of Gatlang VDC of Rasuwa district, Nepal. For the purpose, 30 households were selected purposively. Similarly, four focus group discussions were carried out among the separate group of women, men and group consisting both men and women. Carbon management types: input carbon and output carbon activities were studied on men and women . In total, 23 different agro-pastorals related activities were found, among them $57 \%$ of work were supported by women, $39 \%$ by both men and women, and $4 \%$ by men only. With respect to fuel-wood, in average, $10 \mathrm{~kg}$ per day fuelwood is necessary for one household. The use of biomass for cooking emits chocking smoke and causes indoor air pollution. All these disadvantages lead to carbon emission which might lead to health deterioration of women by increasing the risk of cardiovascular diseases and respiratory disorders. The average fuel-wood requirement was found to be $840 \mathrm{~kg} / \mathrm{capita} / \mathrm{year}$ which are found to be higher than the other physiographic regions of Nepal. This is due to use of fuel-wood as only source of energy in the study area. Out of total respondent, it was observed that $30 \%$ literate men allow their wife to make joint decision on the major household issues. Similarly, $3 \%$ literate women respondents took the major decision by their own or jointly with their husbands. On the other hand, $30 \%$ illiterate men and $37 \%$ illiterate women either didn't allow their wife or don't participate in major decision making process. Further, it is revealed from the chi square test that literacy plays major role in decision making $\left(x^{2}=5.625, d f=1, p=0.017\right)$. Similarly, educated women actively join together with their husband in decision making. Moreover, women have high contribution in carbon input and output activities. Therefore, the women education should be promoted to make their equal and strong participation in decision making, which ultimately contribute in carbon input and output activities, through their greater roles in livestock husbandry and fuel-wood management relative to men. Further, importance of women's role in carbon management should be given greater prominence.
\end{abstract}

Key words: Climate Change, agropastoral, Ethnic Group, Grassland, Transhumant pastoralism

\section{Introduction}

From the pre-industrial period to 2010, the atmospheric concentration of $\mathrm{CO}_{2}$ has increased by $39 \%$, from 280 ppm to 390 ppm (Shang et al., 2016). The growth in the global budget of atmospheric $\mathrm{CO}_{2}$, which includes two major anthropogenic forcing fluxes: $\mathrm{CO}_{2}$ emissions from fossil fuel combustion and industrial processes, and the $\mathrm{CO}_{2}$ flux from land-use change, mainly land clearing (Sabine et al., 2004). There has been a growing attention on the need to tak e into account the effects of global climate

*Corresponding author, email address: rdeshar@cdes.edu.np change. This is particularly so with respect to the increasing amount of greenhouse gas emissions from the developed countries affecting poor indigenous peoples, especially those living in high altitude regions of developing countries.

There are over 350 million indigenous persons, comprising 5,000 different aboriginal tribes, who live in more than 70 countries throughout the world. The effects of climate change on high mountain cultures or alpine regions, such as the Mount Kilimanjaro 
region of Tanzania in East Africa, the Tibetan Mountain Region in Central Asia, and the Andean Region in South America. In all of these highly mountainous countries, which have large populations of culturally unique indigenous or tribal peoples, there are threats posed by retreating glaciers and changing resource bases (Salick \& Byg, 2007).

Transhumant pastoralism is the seasonal migration of livestock and humans between many agro-ecological zones. It is an age-old practice in many mountain regions (Byers, 1996; Rota \& Sperandini 2010). In the Himalaya, for more than 1000 years pastoralists have transformed the ecosystem into economically productive assets for their livelihoods, and even today the region provides a home for a large number of people dependent on livestock (Byers, 1996; Kreutzmann, 2012; McVeigh, 2004; Miller, 1995). In grasslandlivestock production in many mountain areas, the role of women and men differ substantially (Khadka et al., 2014; Shang et al., 2016; Verma et al., 2012) and other pastoral communities (Radel \& Coppock, 2013) and their contribution to carbon balance can differ greatly (Cecelski, 2000; IFAD, 2004; Stevens, 2008). Due to traditions and religious beliefs in Tibetan region, women undertake most of the heavy labor associated with agriculture and livestock production (Dong et al., 2003), while men handle most of the decision-making. As a result, the physical actions of women are integrally involved in carbon input and output, through their roles in livestock husbandry and fuel management, much more than men. In essence, their daily activities are the k ey to the carbon cycle in alpine grassland ecosystems. In alpine grassland areas, women have been involved in carbon management, through management of animal by-products, fuel management, and so on. Their daily labors are the k ey to maintaining the well-balanced carbon cycle in alpine grassland ecosystems.

The Hindu Kush Himalayan region reveals, immense women's contributions to the conser vation and management of forests, ecologically sensitive areas, water springs, and biodiversity resources (Gurung et al., 2011; K arki \& Gurung, 2012; Khadka \& Verma 2012; Khadka et al., 2014; T alukdar, 2012). However, their participation in decision-making and benefit sharing is poor throughout the region (Bhasin, 2011; Parajuli et al., 2010). The majority of women have unequal access to productive resources such as land, enterprise, education, skills, infomation and decisionmaking process (Gurung et al., 2011). Therefore, the study on gender based agro-pastoral activities, their contribution on carbon management and their decision making process in Tamang ethnic community of Gatlang VDC of Rasuwa District, Nepal, has been studied.

\section{Materials and Methods Study area}

The study was carried out in Rasuwa district of Central Nepal (Fig. 1). This district lies in $27^{\circ} 55^{\prime}$ to $28^{\circ} 25^{\prime} \mathrm{N}$ latitude and $85^{\circ} 00^{\prime}$ to $85^{\circ} 50^{\prime}$ E longitudes. The altitude of Rasuwa district ranges from $617 \mathrm{~m}$ to $7227 \mathrm{~m}$ within $1512 \mathrm{sq}$. $\mathrm{km}$ area. Administratively, the northern region of Rasuwa districts is divided into eight VDCs: Timure, Birdim, Langtang, Syabru, Goljung, Gatlang, Thuman and Chilime. Among these VDCs, Gatlang VDC was selected for the study.

Gatlang, one of the VDCs of R asuwa district, is geographically located at middle hill $(2200 \mathrm{~m})$ and lies in temperate zone. According to the Centre Bureau of Statistics (2011), there are 400 household with 1,805 inhabitants of whom 888 are male and 917 are famale. The small population of the village is dominated by Tamang tribal people, one of the indigenous tribes of Nepal, and very few number of Kami (blacksmith).

\section{Research Approach}

The study was carried out in agro-pastoralist community of Rasuwa district. The study covers Gatlang VDC of Rasuwa district, where the transhumane High Himalayan grasslands livelihood activites are found. Thirty households of Tamang ethnic group were selected purposively because the Gorkha earthquake that took place in Nepal on $25^{\text {th }}$ April, 2015 has damaged most of the houses and families were living far from the village. Considering the situation, only thirthy household living in the peripher y of village were considered. The respondents selected for the study covers mainly those who are directly and indirectly link ed with agro-pastoral livelihood. All agropastoral related livelihood activities were considered. Similarly, four focus group discussions were carried out with female, male and mixed (both male and female) respondents group. Gender based carbon management types: input carbon and output carbon activities were studied.

\section{Results and Disucssion}

Male and female labor in agro-pastoral activities and their contribution in carbon input and output activities

The focus group discussion with separate group of female and male, and mixed group revealed that the occupation of Gatlang's people are mostly agro-pastoral based. The village suitable for crops is generally found in the vicinity of the main villages. Climatic conditions differ markedly over short distances owing to the wide altitude variation, permitting several growing seasons and variety of crops. Thus, in the Gatlang region, cultivated land grow potato, maize, millet, barley, beans, lentil and soybean. The staple diet consists of maize and potato. In average, $2000 \mathrm{~kg}$ of potato is grown by most households, but half of their production is sold in the market in order to buy other food products that are not grown in the village. Food products such as rice, which is eaten during special occasion and oil, salt, spices, ghee and lentil are brought from Syafrubesi, a market nearby Gatlang. Most families own land, but the size of holding varies. The produce from the land is just sufficient for about three to four months. In total, twenty dominant agro-pastoral related labor were studied (Table 1). Among them, eleven (57\%) dominant labor related to agropastoral were found to be done by women and eight (39\%) by both men and women, and one (4\%) by only men (Fig. 2). 


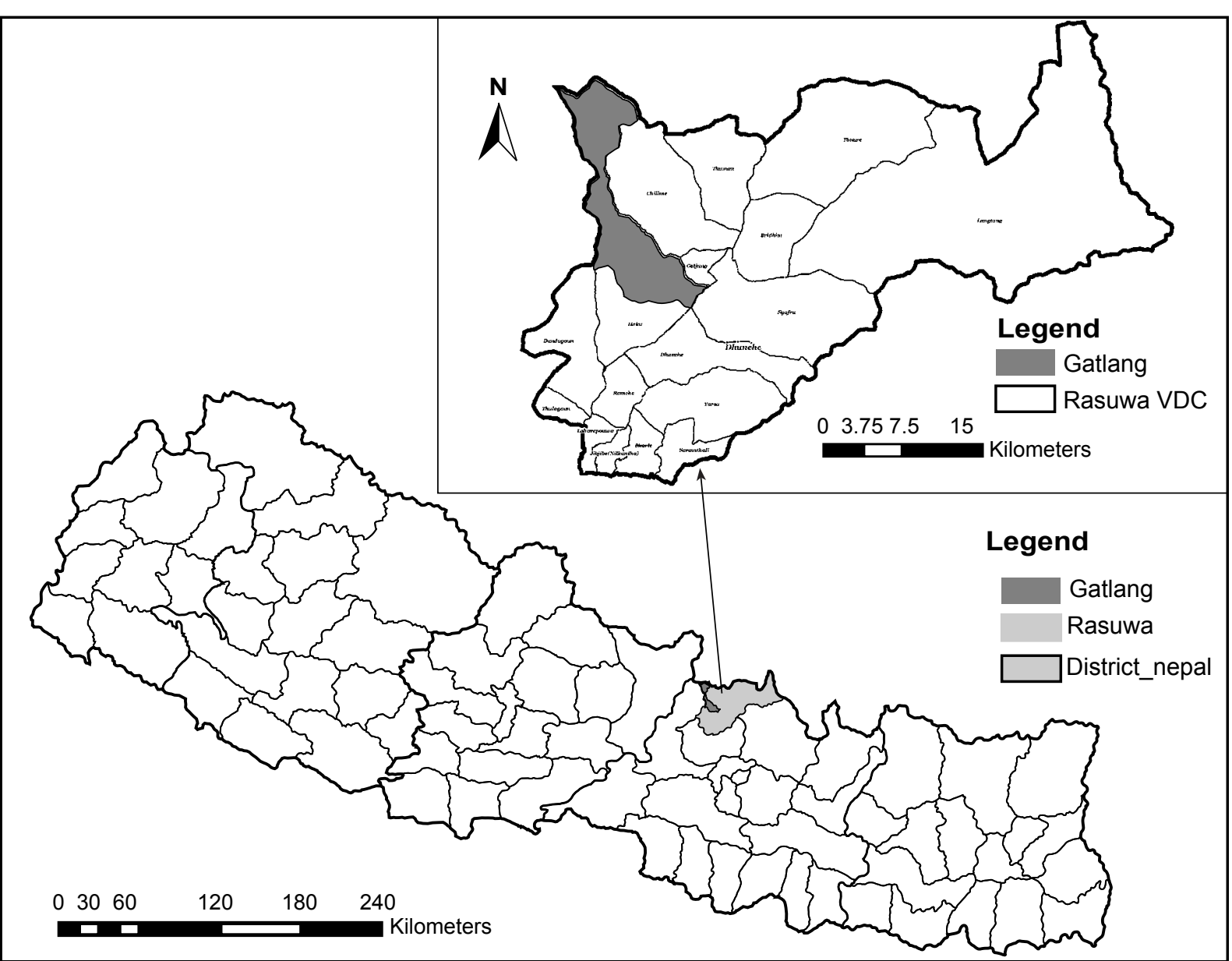

Figure 1 Location map of the study area

Table 1: Gender wise labor dominance in agro-pastoral of the Gatlang VDC

\begin{tabular}{|c|c|}
\hline Agro-pastoral labors & Genderwise labor \\
\hline $\begin{array}{l}\text { Cooking lunch and dinner, cooking food of } \\
\text { livestock, fetching water, washing, firewood } \\
\text { collection from forest, grass collection from } \\
\text { forest, leaf litter collection from forest, dung } \\
\text { collection, scouring wool and spinning wool, } \\
\text { weaving, seeding and labour exchange } \\
\text { (Parma) }\end{array}$ & Women \\
\hline $\begin{array}{l}\text { Timber collection and chopping wood, } \\
\text { milking, transporting of milk to cheese } \\
\text { factory, grazing livestocks, raising and } \\
\text { collecting livestocks, Sheep shearing, } \\
\text { fertilizing, cultivation and har vesting }\end{array}$ & Men and women \\
\hline Ploughing & Men \\
\hline
\end{tabular}

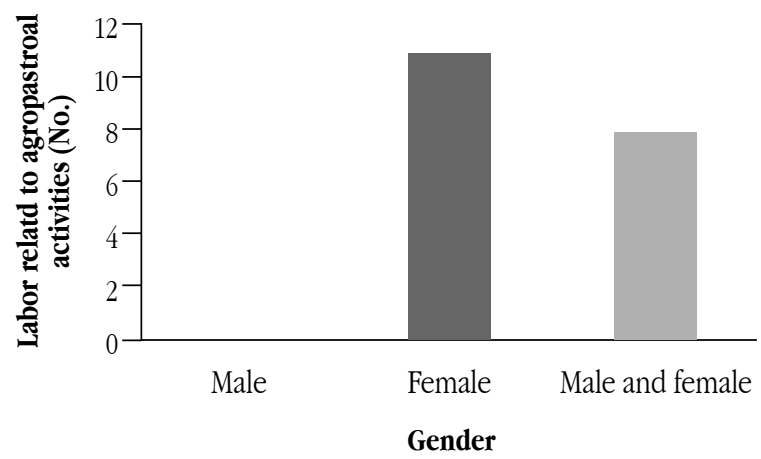

Figure 2 Number of labor dominance of agro-pastoral activities and gender based role

At the time of crop planting and harvesting, both men and women work together in field. The most of the work related to agriculture is performed by individual family members, particulartly ploughing using a personally-owned ploug or borrowing oxen from the other families, who own them. However, some particularly laborious and labour-consuming tasks are carried out in small groups ususally of kin or friends, such as weeding, planting millet, and reaping. 
The need for labor force is fulfilled in three ways-using the family members, hiring labor and adopting labor exchange known as "parma". Weeding is generally done by women, reaping by mixed groups and ploughing always by men. Women undertake almost all of the agriculture activities such as planting, weeding, manuring and harvesting. The male members were busy with livestock and other labor work during day. The timber collection and chopping of wood are the responsibilities of men. However, women are busy in parma and weaving. The typical daily activity of Gatlang's women include at least eighteen hours of continuous workload. In comparison to female, although male per formed hard work, working hour is relatively less (Table 2).

\section{Male and female labor contribution in carbon input and output activities}

Further, the study also tried to find out those agro-pastoral activities in Gatlang VDC, that are directly related with carbon input (Table 3) and output activities (Table 4). The carbon output activities such as cooking, burning, boiling, milk warming, shrubs and tree felling, litter collection, dung collection from range land (Plate 1) and firewood collection are mainly carried out by women. Similarly, another source of carbon output in the carbon cycle was seen from the sale of livestock products such as milk, meat, leather and woolen cloths to areas inside and outside the grassland ecosystem. Traditional handloom is used for weaving $\mathrm{r}$ ugs and bakbhu (overcoat) made from wool of sheep, Chauri an d Yak. Manure storage methods and the amount of exposure to oxygen and moisture can produce in the formation of greenhouse gases such as methane $\left(\mathrm{CH}_{4}\right)$. In the study area, the dung was found to be collected from the grazing area by women and piled in one place (Plate 1) which is later used as manure in the field. This activity release methane gas in the atmosphere. Capturing $\mathrm{CH}_{4}$ from manure decomposition to produce biogas, a renewable biogas energy was not found in the study area. The study found that livestock dung is used only as fertilizer, but for cooking they use fuelwood which has caused deterioration of many forest areas.

Sale of Chauri milk and transporting milk to cheese production factory is very common in Gatlang village. The cheese factor y which collects milk is located in a place near to grazing. When the grazing is shifted to high land during summer, a cheese factory also moves together with livestock with all the required utensil

Table 2 Daily work calendar of a family of the Gatlang VDC, Rasuwa

\begin{tabular}{|c|c|c|}
\hline Time & Husband & Wife \\
\hline $4: 00$ & Sleeping & Get up from bed \\
\hline $5: 00$ & Get up from bed & \multirow{2}{*}{$\begin{array}{l}\text { Milking, cook food for livestock, fetch water, cook } \\
\text { breakfast and lunch, wash cooking utensils and } \\
\text { cloths }\end{array}$} \\
\hline $\begin{array}{l}6: 00 \\
7: 00 \\
8: 00\end{array}$ & $\begin{array}{l}\text { Drink tea and go to sale milk in cheese } \\
\text { factory }\end{array}$ & \\
\hline $9: 00$ & Return back home for lunch & Eat lunch only after serving food to all family member \\
\hline 10:00 & Take rest & \multirow[b]{2}{*}{$\begin{array}{l}\text { Wash cooking utensils, go to collect firewood, grass } \\
\text { and leaf litter from forest and go to look after } \\
\text { livestocks and collet dung from grazing area. During } \\
\text { the season of plantation and harvesting go to field } \\
\text { and work. Also practise labour exchange (Parma) } \\
\text { for seeding, planting and harvesting with neighbours. }\end{array}$} \\
\hline $\begin{array}{l}11: 00 \\
12: 00 \\
13: 00 \\
14: 00 \\
15: 00\end{array}$ & $\begin{array}{l}\text { Go to grazing land and look after livestocks } \\
\text { or go to field during the season of plantation } \\
\text { and harvesting. }\end{array}$ & \\
\hline $\begin{array}{l}16: 00 \\
17: 00 \\
18: 00\end{array}$ & Return back home and take rest & $\begin{array}{l}\text { Return back from grazing land or agriculture land } \\
\text { and start scouring wool and spinning wool and } \\
\text { weaving }\end{array}$ \\
\hline 19:00 & & Fetch water and cook dinner \\
\hline 20:00 & Have dinner and go to bed & $\begin{array}{l}\text { Serve dinner to all family members and have dinner } \\
\text { Wash cooking utensils and clean kitchen. }\end{array}$ \\
\hline $\begin{array}{l}21: 00 \\
22: 00\end{array}$ & Go to bed & $\begin{array}{l}\text { Scouring, spinning and weaving of wool and prepare } \\
\text { woolen cloths. Also practiceParma (labor exchange) } \\
\text { between neighbors for wool waiving and preparing } \\
\text { woolen cloths. }\end{array}$ \\
\hline $23: 00$ & & Go to bed \\
\hline
\end{tabular}


and equipments for making cheese. Pastoral related activities includes milking, firing, cooking, firewood and litter collection, grazing livestock, collecting and drying manure, shearing, scouring and spinning of wool and waiving of woolen cloths, which directly and indirectly contribute to carbon output (Table 2). In all these activities, women are more responsible than men.

Table 3 Carbon output activities of male and female

\begin{tabular}{ll}
\hline Carbon output activities & Gender wise role \\
\hline $\begin{array}{l}\text { Cooking, bur ning, water boiling, milk } \\
\text { warming, wool shearing, scouring, spinning }\end{array}$ & Women \\
and waiving of woolen cloths & \\
$\begin{array}{l}\text { Collecting firewood, dead tree cutting, and } \\
\text { cultivation and harvesting }\end{array}$ & Men and women \\
$\begin{array}{l}\text { Tree feeling, chopping of wood, making } \\
\text { cheese, sale of milk and meat }\end{array}$ & Men \\
\hline
\end{tabular}

Table 4: Carbon input activities of male and female

\begin{tabular}{lc}
\hline Carbon input activities & Gender wise role \\
\hline Grassland management, plantation of crop, & Men and women \\
wool shearing, scouring, spinning and & \\
weaving of woolen cloths & \\
Cowdung collection for manure & Women \\
\hline
\end{tabular}

The Gatlang VDC of Rasuwa district is typified by the traditional open fire wood stoves (a tripod type) without chimney and good ventilation, symbolizing primitive cooking practices, which are generally used in many regions of Nepal (Plate 2). F rom focus group discussion, it was found that for cooking purpose, the required energy is obtained from fuelwood. According to the Central Bureau of Statistic (2011), among 400 total household of Gatlang, 398 household used firewood for cooking. Only one household was found using kerosene for cooking. During the field visit on March, 2016, 30 households under sur vey were found using firewood. Among these housholds, five households had switched to liquefied petroleum (LP) gas of $14.2 \mathrm{~kg} /$ cylinder for cooking, but still they are not fully dependent on it. In average, $0.3 \mathrm{~kg} /$ day LP gas is consumed by households, which is equal to half cylinder (7.1 kg/cylinder) per month (Fig. 3).

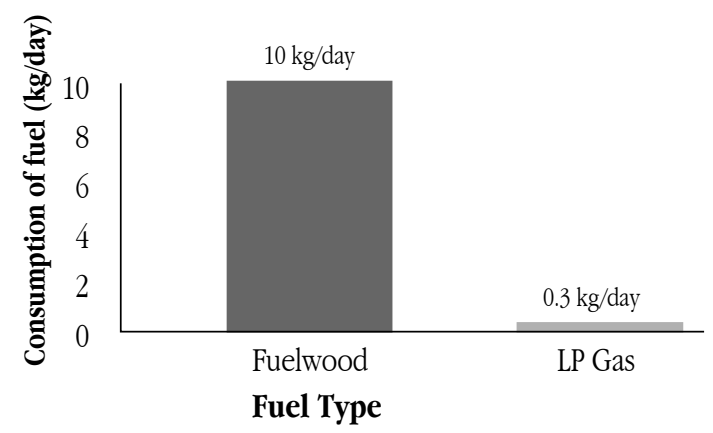

Figure 3 The average fuelwood and LP gas consumption of Gatlang VDC, Rasuwa

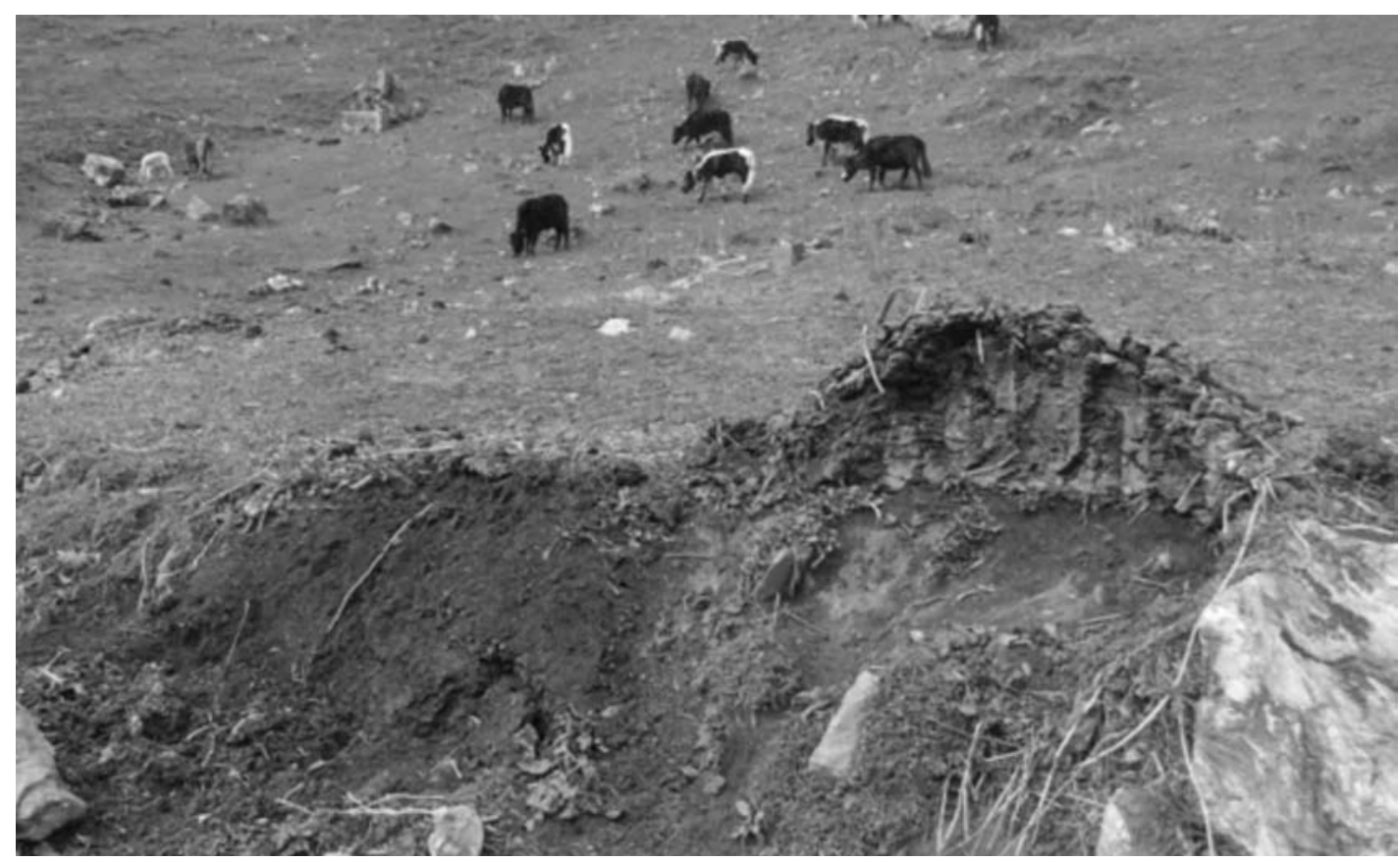

Plate 1 A pile of cow dung collected near range land of Gatlang VDC, Rasuwa 


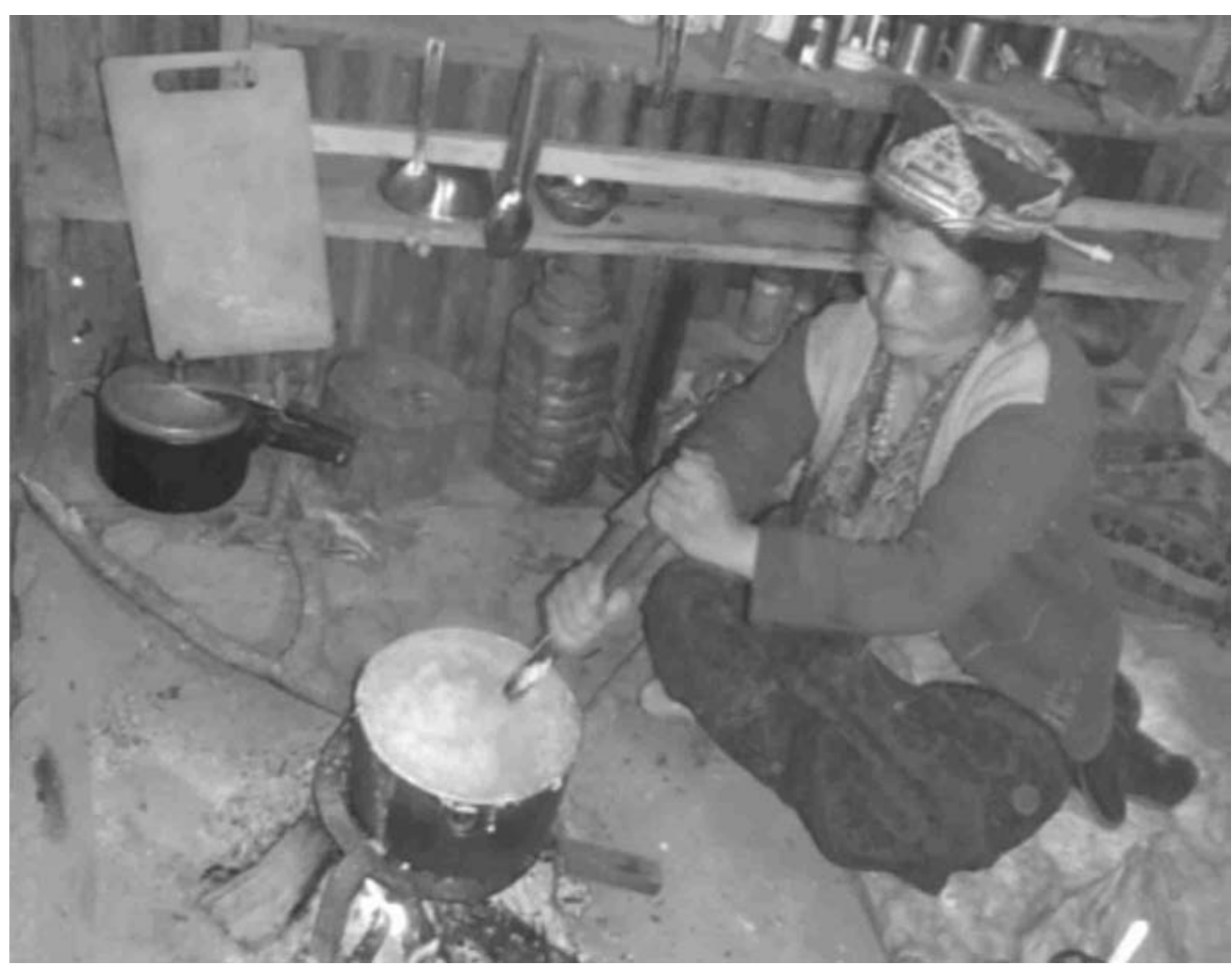

Plate 2 Women of Gatlang VDC cooking in the traditional open firewood stove.

Furthermore, in average, $10 \mathrm{~kg}$ of fuelwood is necessary for one household for one day (Fig. 3). The cooking activities includes: cooking food, warming water and food for livestock, war ming milk and occassionally making alcohol. The dead trees are used as fuelwood, which is collected from the nearby forests mostly by women, when they visit grazing area with livestock. The dung of livestock is not used for cooking purpose, instead, it is used as manure in the field. The biogas plant was not found in Gatlang VDC. In the pastoral regions of the Tibetan Plateau of China, the collection of livestock dung for the use of fuel instead of fuelwood is very common. Yak dung is an important source of fuel in area, where firewood is not available (Miller, 1999). Most Tibetan families use only Yak dung for cooking and heating as their limited income does not allow them to purchase fossil fuels. Families live in either tents or stone homes and, for economic reasons, mainly use simple stoves without chimneys (Xiao et al., 2015).

In Gatlang VDC, people are still unable to replace wood and other forms of biomass for cooking with moder $n$, convenient and pollution free LP Gas. The bur ning of fuelwood emits chocking smoke and causes indoor air pollution. All these disadvantages lead to carbon emission, which might lead to health deterioration of women by increasing the risk of diseases such as cardiovascular diseases and respirator y disorders. W omen might be most vulnerable to these health hazards, as they do the cooking and spend most of their time near the fire. Nevertheless, five households under home-stay and tourist business were found using LP gas. With the good excess of road to Gatlang, the LP cooking gas of $14.2 \mathrm{~kg} /$ cylinder were found to be used by some households, who are running guest house and home-stay. The people belonging to such small entrepreneurship were found to use LP gas, when they need to cook less amount of food immediately. The small cottage based entrepreneurs are not fully depending on LP gas, since households have supplement of fuelwood from the forest, which has increased deforestation in the study area. The dependency of households on LP gas is very minimal. In average, one cylinder LP gas is enough for two months. From 30 household surveyed in Gatlang VDC, the average fuel-wood requirement was found to be $840 \mathrm{~kg} / \mathrm{capita} / \mathrm{year}$, while FRA (2000) has reported fuel-wood requirement for Mountain region and Tarai region respectively to be $640 \mathrm{~kg} / \mathrm{capita} /$ year and $479 \mathrm{~kg} / \mathrm{capita} /$ year (Fig. 4).

Physiographically, the per-capita requirement of fuel-wood is more in the Mountain region than Tarai region. In case of Gatlang VDC, the requirement is even higher than Mountain regions. Further, the study carried out in Western Hills of Nepal has estimated the average per capita fuel-wood consumption to be 506.48 $\mathrm{kg} / \mathrm{capita} /$ year, which is lower than the Gatlang VDC. This is due to use of fuel-wood as only source of energy as well as due to cold weather in Gatlang VDC. In addition, W estern Hill households also use crop residue as fuel.

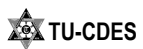




\section{Women in household decision making}

Figure 5 shows the percentage of women and men who reported that they make specific household decisions alone or jointly with their spouse. The result shows women's autonomy in minor household decisions like purchasing daily household goods- rice, lentils, spices and cloths. But, for the major household decisions like purchasing jeweler, land, livestock (Cow, Yak, Chauri), the women need to take consent from husband.

Out of the total respondents, it was obser ved that $30 \%$ literate male allows their wife to take major household decision jointly. Similarly, 3\% literate female respondents took major decision either lonely or jointly with their husbands. On the other hand, $30 \%$ illiterate male and 37\% illiterate female respondents either do not allow their wife or they don't participate in the major decision making process. Further, it is revealed from the chi square test that literacy plays major role in decision making $\left(x^{2}=5.625\right.$, $\mathrm{df}=1, p=0.017$ ) in both male and female respondents. This is because the educated men allows their wife to join together with husband in household decision. Similarly, educated women themselves actively join together with their husband in decision making. Therefore, education of women should be promoted so that women can mak e equal and strong participation in household decision. Further, the important women's role in carbon management should be given greater prominence.

In terms of ownership to fixed assets and property such as land, building and livestock, women of Gatlang were found to have lack of access. Furthermore, in ter ms of property right, the result showed women have no rights on land and property ownership. This might have lowered confidence of women in major decision making process. Therefore, women should be provided credit for their roles in the major household decision. Such credit could support livestock production and management for the promotion of women's economic and social empower ment. However, for making minor decision of household, women don't need any consent from their husband. Despite their academic qualification, women are still found to be active in social activities. Women were found to have more confidence in taking minor decision in their household matters, which is contradictory to the study found by $\mathrm{Lu}$ (undated) in Tibetan region of China. Due to traditions and religious beliefs in Tibet, women undertak e most of the heavy labor associated with agriculture and livestock production (Dong et al., 2003), while men handle most of the decision-making.

Nepal, like most societies in the South Asia, was rigidly patriarchal society, in which most of the women receive little or no for mal education and have limited access in the household decision making (Paudel, 2011; Tamang, 2000; WHO, 2009). The condition of women is strictly controlled by patriarchal norms of the society (Acharya, 1994). Men occupy virtually every aspect of life, whereas women were generally subordinate to men. Nonetheless, women's relative status, varied from one ethnic group to another

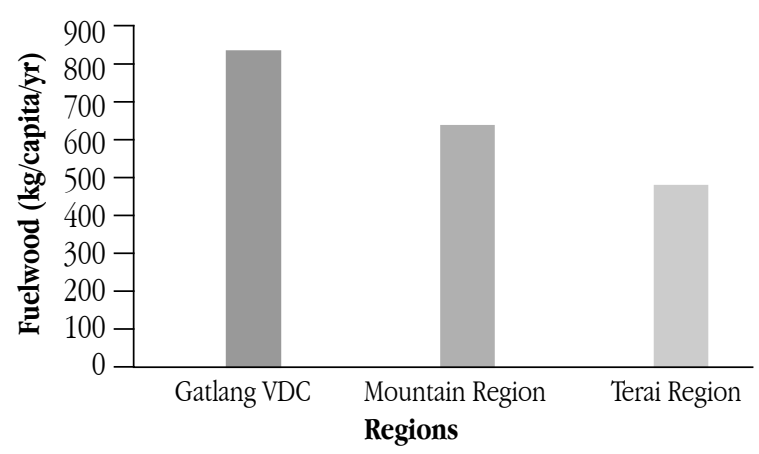

Figure 4 The per capita fuelwood consumption in different region of Nepal (FRA, 2000)

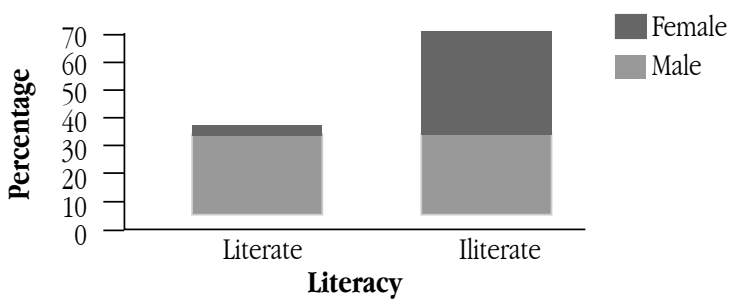

Figure 5 Participation of men and women in decision making

The status of women in Tibeto-Nepalese communities generally, was relatively better than that of Pabari (hilly) and Newari women. Women from high Himalayans regions enjoyed relatively more autonomy and freedom than Pabari of hilly region and Newari women (Bhandari, 2012).

\section{Conclusion}

The Gatlang VDC of Rasuwa district reveals that majority of the labor related to agro-pastoral activities are carried out by women in compared to men. Women are more social and engaged in collective works. For minor household purchases, women don't need to take consent, but for major household purchase women need to take consent from their husbands. Although, women might have not influenced in the major decision making process, their role in agro-pastoral related activities have played the major role in carbon output and input. Further, the physical actions of women are integrally involved in carbon balance, through their roles in livestock husbandry and fuelwood management, much more than men. In essence, their daily activities are the key to the carbon cycle in high altitude grassland ecosystems. Therefore, the study recommends that education of women should be promoted so that women can mak e equal and strong participation in household decision. Further, the important role of women in carbon management should be given greater prominence and better acknowledged the key role of high-land people, specially women in maintaining grasslands through their sustainable landscape management. 


\section{Acknowledgements}

This study was supported by Himalayan University Consortium, seed grant. The authors are grateful to Prof . Shang Zhanhuan, School of Life Sciences, L anzhou University, PR China for his support. Likewise, the authors are also grateful to the local communities of Gatlang, Rasuwa.

\section{References}

Acharya, M. (1994). The statistical profile on Nepalese women: an update in the policy context. Kathmandu, Nepal, Institute for Integrated Development studies.

Bhandari, K. K. (2012). Exploration of women's role in household decision making by caste and ethnicity: A Study of Dhangadhi Municipality, Kailali. Social Inclusion Research Fund SNV, Netherlands Development Organization.

Bhasin, V. (2011). Status of women in transhumant societies. Journal of Sociology and Social Anthropology, 2(1), $1-22$.

Bhattarai, L. N. (2013). Exploring the determinants of Fuel wood use in Western Hill Nepal: An Economic Analysis. Economic Literature, 11, 26-34.

CBS, (2011) National Population and Housing Census. Central Bureau of Statistics, Kathmandu.

Cecelski, E. (2000). The Role of Women in Sustainable Energy Development. National Renewable Energy Laboratory. Golden, CO. http://dx.doi.org/10.2172/758755

Dong, S. K., Long, R. J., \& Kang, M. Y. (2003). Milking and milk processing: traditional technologies in the yak farming system of the Qinghai-'5fTibetan Plateau, China. International journal of dairy technology, 56(2), 86-93.

Gurung, J., Giri, K., Setyowati, A. B., \&Lebow, E. (2011).Getting REDD+ right for women: an analysis of the barriers and opportunities for women's participation in the REDD+ sector in Asia. United States Agency International Development, 1113 .

IFAD (2004). Enhancing the Role of Indigenous Women in Sustainable Development. Third Session of the PermanentForum on Indigenous Issues. International Fund for Agricultural Development. Accessible online at:http://www.ifad.org/english/indigenous/pub/documents/in digenouswomenReport.pdf(accessed 2 September 2016).

IPCC (2007). Climate Change 2007. The IPCC, 1996, Revised 1996 IPCC Guidelines for National Greenhouse Gas Inventories.

Karki, S., \& Gurung, M. (2012). Women's leadership in community forestry in the middle hills of Nepal. Gender and biodiversity management in the Greater Himalayas: towards equitable mountain development. ICIMOD, Katbmandu, Nepal, 25-27.

Khadka, M., \& Verma, R. (2012). Gender and biodiversity management in the Greater Himalayas: towards equitable mountain development. International Centre for Integrated Mountain Development (ICIMOD).
Khadka, M., Karki, S., Karky, B. S., Kotru, R., \& Darjee, K. B. (2014). Gender equality challenges to the REDD+ initiative in Nepal. Mountain Research and Development, 34(3), 197-207.

Kreutzmann, H. (2012). Pastoralism: A Way Forward or Back? In Pastoral practices in High Asia (pp. 323-336). Springer Netherlands.

Lu, M. [undated]. 'Family and women among nomads of northern Tibet'. Accessibleonline at: www.cwru.edu/affil/tibet/booksAndPapers/Gelek/Mei.pdf (accessed 24October 2015).

McVeigh, C. (2004). Himalayan herding is alive and well: the economics of pastoralism in the Langtang valley. Nomadic peoples, 8(2), 107-124.

Miller, D. (1995). Nomads of the Tibetan Plateau Rangelands in Western China Part Two: Pastoral Production Practices. Rangelands, 21 (1), 16-19.

Miller, D. (1995). Herds on the Move: Winds of Change Among Pastoralists in the Himalayas and on the Tibetan Plateau. Kathmandu, Nepal: International Centre for Integrated Mountain Development.

Parajuli, R., Pokharel, R. K., \& Lamichhane, D. (2010). Social discrimination in community forestry: Socio-economic and gender perspectives. BankoJanakari, 20(2), 26-33.

Paudel, S. (2011).Women's concerns within Nepal's patriarchal justice system. Ethics in Action, 5(6).

Radel, C., \& Coppock, D. L. (2013). The World's Gender Gap in Agriculture and Natural Resources: Evidence and Explanations. Rangelands, 35(6), 7-14

Rota, A., \& Sperandini, S. (2009). Livestock and pastoralists. IFAD: Livestock Thematic Papers - Tools for Project Design. Rome.

Salick, J., \& Byg, A. (Eds.).(2007). Indigenous peoples and climate change. Oxford: Tyndall Centre for Climate Change Research.

Shang, Z., White, A., Degen, A. A., \& Long, R. (2016). Role of Tibetan Women in Carbon Balance in the Alpine Grasslands of the Tibetan Plateau. A Review. Nomadic Peoples, 20(1), 108122.

Stevens, C. (2008). Gender and Sustainable Development: Maximising the Economic, Social and Environmental Role of Women.Organisation for Economic Co-operation and Development. Accessible online athttp://www.oecd.org/social/40881538.pdf (accessed 2 September 2016).

Tamang, S. (2000). Legalizing state patriarchy in Nepal. Studies in Nepali History and Society 5(1): 127-156.

WHO (2009). Perspectives on sexual violence during early years of marriage in Nepal: findings from a qualitative study: social science research policy briefs. World Health Organization, Nepal.

\section{盽 TU-CDES}

